\title{
In Storage, Yet on Display
}

\author{
An Empirical Investigation of Robots' Value as Social Signals
}

\author{
Matthew I. Beane \\ Technology Management \\ University of California, Santa Barbara \\ Santa Barbara, California, USA \\ mattbeane@ucsb.edu
}

\begin{abstract}
This paper suggests that humans value robotic systems as signals - costly, visible commitments that can secure access to preferred resources. This contrasts with HRI research, design, engineering and deployment, which have focused on robots' instrumental value - namely how designing and interacting with them may produce more or less productivity. Drawing on a multiyear ethnography of a "failed" robotic telepresence deployment in a teaching hospital, this paper shows that robots' signaling value can significantly outweigh - and even contravene - any practical utility that they may provide through use. This analysis further suggests that - unlike nontechnological organizational signals - robots' signaling value is highly contingent on the observability of their use. Considering robots' signaling value in complex social systems such as organizations promises improved robotic systems development and deployment techniques and improved prediction regarding human-robot interaction.
\end{abstract}

\section{CCS CONCEPTS}

- HRI theory, concepts and models - Ethnographic studies Empirical studies in HRI

\section{KEYWORDS}

HRI theory, Signaling theory, Ethnography, Robotic telepresence

\section{ACM Reference format:}

Matthew I. Beane. 2020. In Storage, Yet on Display: An Empirical Investigation of Robots' Value as Social Signals. In Proceedings of 2020 ACM/IEEE International Conference on Human-Robot Interaction (HRI'20), March 23-26, 2020, Cambridge, United Kingdom. ACM, New York, NY, USA, 9 pages. https://doi.org/10.1145/3319502.3374775

Permission to make digital or hard copies of all or part of this work for personal or classroom use is granted without fee provided that copies are not made or distributed for profit or commercial advantage and that copies bear this notice and the full citation on the first page. Copyrights for components of this work owned by others than ACM must be honored. Abstracting with credit is permitted. To copy otherwise, or republish, to post on servers or to redistribute to lists, requires prior specific permission and/or a fee. Request permissions from Permissions@acm.org. HRI '20, March 23-26, 2020, Cambridge, United Kingdom

(C) 2020 Association for Computing Machinery.

ACM ISBN 978-1-4503-6746-02/20/03...\$15.00

https://doi.org/10.1145/3319502.3374775

\section{Introduction}

Robots mean something to us beyond the instrumental results they provide. We take pride in studying and building them, we seek to commercialize or profit from them, we protest against or sabotage them, and a growing number of us trust and collaborate with them to get work done. And as these examples suggest, we typically produce and assess robots' value in complex social settings: building, selling, buying, using and even talking about robots often proceeds through organizations of some kind, which are in turn embedded in industries, occupations, legal systems, communities, national cultures and the like. Available field research shows these dynamics playing out in very different ways in settings such as hospitals [1], technology startups [2], scientific work [3], manufacturing [4] and the military [5].

Now more than ever, we need to work towards theory that accounts for the full range of value that we seek from robots [6]. Robotic systems development and deployment are exploding worldwide, as are pressures for robotic systems to react appropriately in dynamic and complex social settings. Furthermore, robots are the impetus for increasingly consequential prediction and decision making [7], [8]. Better theory that accounts for direct human-robot interaction and the full range of value provided by robots will allow us to predict HRI more effectively and to make more useful choices as we engage in crucial robotics-related work such as design, development, marketing, sale, deployment, fundraising, policy making and continuous improvement.

HRI-related research has generally analyzed robots with an eye to their functional value - more or less effective means of achieving an instrumental outcome. Thus, studies have explored designs and deployment conditions that may lead users to interact more fluidly with a given robotic system, focusing on problems such as learning from joint action [9], anticipatory control [10], repairing social breaches [11], soliciting human assistance [12] and developing trust [13]. Such basic advances are typically motivated as enhancing the pursuit of one or more instrumental goals such as collaborative control of complex equipment [14], joint product assembly [15], disaster response [16] and data collection in remote environments [3]. HRI research has not yet explicitly theorized the ways that robots 
may add value as signals - costly, observable commitments that can secure access to preferred resources [17].

In this inductive study, I show how displaying investments in robotic systems can send strong signals to critical stakeholders (e.g. customers, donors, workers) and that this can reliably induce interpretation and action favorable to the investing organization. I further show that such signaling value can be significant even when acquired robots are used erratically or interpreted unfavorably by potential users. Framed positively, I find that an investment in "cutting edge" robotics can send signals that facilitate valuable outcomes such as business development, fundraising, brand awareness, organic customer acquisition and employee and customer satisfaction. To derive these findings, I draw on a multi-year ethnographic study of a hospital-wide deployment of multiple robotic telepresence systems. I explore how and why these systems added value despite the fact that they saw only intermittent use and the organization got quite a poor traditional return on its investment in them. This analysis was possible because my data is longitudinal and fine-grained, depicting interactions and interpretation in a wide range of work-related situations over a number of years [18], [19].

This new perspective enriches current HRI research agendas in three ways. First, it broadens our view on the value we seek from robots: whether or not it seems appropriate, visibly interacting with (e.g. acquiring, using) robotic systems can signal underlying quality, and resultant status and legitimacy enhancement can enhance access to preferred resources. Second, it extends how we might study human robot interaction by going beyond instrumental results and productivity to understand how information about interaction with robotic systems may have more beneficial (or detrimental) consequences than the robot itself does in practice. Third, and relatedly, this work suggests that HRI researchers can expand their relevance and impact by studying organizational practices that shape interpretation regarding robotic systems, such as marketing, fundraising and business development.

\section{The Value of Robots in Prior Research}

Prior HRI research has generally focused on how robots may interact more effectively with humans towards some instrumental goal. More basic research has done so by focusing on interaction fluidity, for example through nonverbal behavior [20], interfaces for multiagent control [21] and autonomous policy explanation [22]. Such work promises to influence processes that enable a wide range of potential specific applications. More applied research has focused directly on efficacy and utility in contexts such as fire suppression [23], human-robot collaborative flight [14], upper limb rehabilitation [24], in-building navigation assistance [25] and home cleaning [26]. Such work examines deployments with an eye to demonstrating, enhancing or explaining the effectiveness of robotic solutions to real world human-interaction problems.
None of this work focuses on how robots may add value as signals - costly, visible commitments that can secure access to preferred resources. This was problematic for analysis of robotic value in my context, in which a hospital's significant investment in robots added little instrumental value (an unsurprising finding, e.g. [27]-[29]) yet facilitated a range of positive organizational outcomes.

In order to account for these noninstrumental sources of robotic value, I grounded my analysis in signaling theory [17], [30], [31], which holds that actors such as organizations make costly, easily-observable commitments to indicate underlying quality. These are sometimes purely symbolic - as in the case of a bank investing in a fine marble façade to signal financial largesse but in many cases involve some blend of symbolic and functional purposes - as in the case of an individual securing an education and putting it on their resume. Signals are often worth their cost as they induce favorable attention and action, even when they are not "honest" - i.e. do not reliably indicate underlying quality [32]. For this study, I specifically drew on work in economics and organization studies that examines the symbolic and signaling value of information [33]-[36] as well as works that suggest that technology may serve as a signal [37]-[40].

\section{Robots as Signals: Telepresence "Failure" at Corel ${ }^{1}$ Hospital}

\subsection{Sample and Method}

I performed this study at Corel, a mid-sized [387 bed] teaching hospital in the northeastern US with 450 physicians, 3000 nurses and support staff and top-tier surgical capacity. Corel had several satellite locations and referral relationships with smaller hospitals. Corel faced stiff competition for patients, talent and donations: it lay within 50 miles of four internationally known, 800-bed hospitals. InTouch Health's RP-7 robotic telepresence system is the focus of this study - state of the art technology in 2007. The RP-7 consisted of a mobile, untethered base with a speaker and a screen-and-cameras "head" at the top, allowing for repositionable, two-way video and audio communication. A remote user drove the base and controlled the head pan and tilt functions via a specialized laptop and mouse, speaking and listening via a wired headset.

This initial target market for the RP-7 was one centered on referral revenue for rapid consultation on stroke patients. Some strokes were caused by hemorrhages (a burst blood vessel in the brain) and were often treated by surgery. Other strokes were caused by a clot that had traveled to the brain. The latter stroke was treatable by a drug called t-PA, but only if it were administered within three hours of stroke occurrence, while treating a hemorrhage patient with t-PA could kill them [41]. Making this diagnosis took a visual and verbal exam by a Neurologist. Before robotic telepresence, many smaller hospitals

\footnotetext{
${ }^{1}$ I have altered details that could identify the institutions and individuals in this study.
} 
faced a dilemma: they could send their stroke patients on a multi-hour journey to a Neurologist, pushing the t-PA timeline, or they could treat conservatively and run a significant practical and legal risk of depriving that patient of a potential cure. Robotic telepresence promised rapid, remote diagnosis, so offered significant instrumental value to all parties: rural hospitals could get remote diagnosis and keep their patients (and related revenue) while urban hospitals could get new diagnosisrelated revenue and some of these patients as transfers at low cost.

I gathered observational data (e.g. near-verbatim typed notes) on use of the RP-7 in Corel's post-surgical ICU nearly every week for 14 months (2010-2012). I also recorded and transcribed 37 formal interviews with administrators, doctors and nurses and took notes on extensive informal interviews with key informants, soliciting accounts for events from before overall RP-7 implementation (i.e. 2007) through the end of my study period (2012). I used standard techniques for qualitative, inductive analysis [42], [43], building from low-level conceptual categorization of my data (e.g. lack of use, outsider attention) through an interpretive lens (e.g. signaling theory) to guide the construction of a theory of the mid-range [44] that accounted for my data while abstracting away from it. The primary value of midrange theory is that generalizes away from the particulars of the case (e.g. the summative figure in this paper makes no mention of hospitals, Rp-7s, patients or healthcare) to plausibly guide explanation and prediction regarding cases that exhibit similar conceptual characteristics.

\subsection{Findings}

\subsubsection{Poor Instrumental Value from Robotic Telepresence} Investment at Corel Hospital

In 2007, a new CEO arrived at Corel hospital and decided in relatively short order to make a significant investment in robotic telepresence technology: by 2008 she had signed a binding sixyear lease for 12 RP-7 units. She and her Vice President for patient relations quickly tapped an up and coming Corel physician specialized in critical care to be "Telemedicine Medical Director" (henceforth TMD) and a mid-level administrator who managed referral relations with other sites to be "Telemedicine Program Director" (henceforth TPD). Both of these were new roles for the organization, and neither of these workers had dealt with robotic telepresence (or any robotic technology) before.

The technology came to me. It was introduced by a vendor to one of our senior administrators and they asked me if I was interested. It's not as if there's a glorious story. It came to me for more my organizational skills and being able to operationalize something. (TMD)

As with many of InTouch's customers, this investment was ostensibly targeted at improved revenue and patient outcomes related to remote stroke diagnosis. In particular Corel's going-in plan was to place RP-7s in smaller, more rural hospitals without neurologists, enabling Corel's Neurologists to make remote diagnosis and treatment decisions. While this promised improved revenue and outcomes for all involved institutions,
Corel expected this investment to "pay" for itself through new transfers:

But at the end of the day, how did we measure our success? How many transfers came to Corel and how long did they stay, and would we have gotten that transfer but for the robot. That's really how you measured your success. It always comes down to money, doesn't it? (TPD)

Thus, formal standards at Corel for an investment in robotic telepresence technology were similar to those associated with investment in complex technology at a wide variety of organizations: each dollar spent should directly lead to a disproportionate return in revenue.

These standards were not met. The economic crisis of 2008 made rural hospitals less interested in investing scarce resources in an unproven telemedicine program. More critically, the Corel's Neurologists realized that on-demand consults impinged unpredictably on their local work and they concluded at about this time that they would be liable for misdiagnoses via the robot, so they declined to use it. This blocked the main impetus for the RP-7 implementation, leaving Corel with five years left on a binding lease for $12 \mathrm{RP}-7 \mathrm{~s}$ and no clear way to recoup this investment.

The telemedicine team struggled to find another sufficiently remunerative use for these systems. Careful consideration of early deployments indicated some potential for using RP-7s for critical care. Critical patients needed regular assessment by physicians who had specialized in ICU care, and rural hospitals struggled to attract and retain such talent.

We do consults at institutions where patients are already getting critical care, but they want a second set of eyes on a complex case, those patients are already very sick, it's not as urgent a consult, we don't have to drop what we're doing. We can schedule that consult later that day. (TMD)

The TMD was familiar with this care modality, so the telemedicine team shifted their deployment efforts in this direction. The TPD managed to place one unit in the Caribbean and three at rural hospitals for this purpose. In the interim, he placed three of the units in storage, and five of the units in Corel's main facility to encourage broader use. This did not have the intended effect:

Our whole strategy was really for us to put these out at community hospitals, but in the meantime, rather than put them here [in storage], we put them on the floor [a unit at Corel] with maybe the idea that maybe our docs could use them to round on their patients. Initially they did a little bit. But it just became, it was obvious that wasn't the intent, we have residents here, we have fellows here, our attendings don't really need to beam into our own robots from home. (TPD)

A deeper problem arose, however: ICU deployments were harder to administer and staff than expected. This was fundamentally a usability problem: specialists had to be willing to develop significant expertise controlling the system over longer stretches of time - driving it throughout an ICU with 15 to 30 beds, 
panning, tilting and zooming their cameras, adjusting their volume.

We tried to train sixty doctors how to work it, most of them didn't really get it or use all the features, so nine times out of ten I'd be off camera working the controls. I would zoom in, zoom out, looking at this, doing the reading. I was kind of the wizard behind the curtain there. (TPD)

These specialists were accustomed to using the telephone to "round" on their remote patients by quizzing a resident [45], so after a few frustrating attempts at rounding via RP-7, they defaulted to their prior practice. The RP-7 units therefore saw very little use.

Thus, by traditional instrumental measures, Corel's robotic telepresence investment secured a poor return: the units were used to help far fewer patients than all had expected, with a concomitant reduction in revenue.

\subsubsection{Significant Signaling Value from Robotic Telepresence Investment at Corel Hospital}

Shortly after her first exposure to the technology through a sales representative, the new $\mathrm{CEO}$ began to insist that robotic telepresence was "the wave of the future in medical care and the hospital should acquire the state-of-the-art equipment." In part this was because InTouch health used their technology to signal they were capable of facilitating discontinuous, positive results to numerous customers in Corel's local market, citing the RP-7s potential to enhance revenue but also to increase brand awareness in a competitive market with strong incumbents. In particular they created and posted demonstration videos on the web, did live demonstrations and interacted in controlled settings around these imagined futures (e.g. sales meetings) to acquire Corel as a customer. After the CEO enlisted the TMD and TPD, InTouch provided them all with a brief demonstration:

[TMD]. and I were invited to attend when InTouch health came in to give a presentation on their brand of telemedicine. Corel wanted to be on the cutting edge of technology [and] was trying to compete with downtown hospitals, and certainly the robot did that. That was an a-ha moment when you see the robot: [Nonrobotic] telemedicine wouldn't distinguish us at all. We were hoping that the robot would be the big differentiator, we'd be first to market. Visicue or EICU [nonrobotic telemedicine vendors] hardwire a room, and you have to bring patient to that room. The robot allows flexibility. (TPD)

After this demonstration, but before widespread implementation, they got further personal exposure to a set of possible deployment approaches and outcomes:

Before we even got going with our first robot, InTouch flew us to Dubuque, Iowa and drove us to this little dinky hospital up in Montana to go and see firsthand how this works. And here you are in this little hospital two and a half hours from anywhere, and these people managing patients you know with the push of a button getting right to the patient's bedside, it really drove the point home for us to see it first hand and to now promote it to other parties. (TPD)

The CEO insisted on taking possession of all $12 \mathrm{RP}-7 \mathrm{~s}$ right away. Beyond engaging with Neurologists, the first step in the internal rollout was "educating" staff. This centered around demonstrations, which involved the TPD driving around the hospital and chatting with passers-by, whether they were patients, staff or physicians.

Purchasing these robots drew external attention in a crowded market faster than the telemedicine team had thought possible. A reporter from a large metropolitan news organization contacted the TMD and CEO before the TPD had begun drafting a formal plan to share information on its robotic telemedicine program:

Someone at the Tri-city Tribune reached out shortly after we implemented, and they sent out a videographer to interview [TMD], and see this robot in action, and it became a front-page story in the Tribune. Right out of the gate we got huge bang for the buck. (TPD)

Beyond its immediate value as an indicator of Corel's quality and technical sophistication, this unsolicited media attention helped the TPD in acquiring new relationships and new revenue, in that it provoked new conversations with potential customers and donors:

That [news story] gave us traction, that gave us credibility, that gave us the "this is out there, this is up and running, we can do this." So, it became part of my presentation when I would go to other hospitals in a hundred-mile radius of Corel to get them to partner with us." (TPD)

There was one donor that was involved in another program to help fight cardiac disease. He was able "connect the dots" and could see how the robot could also potentially help fight cardiac disease. While he did not specifically earmark money for the robot, he understood what we were doing and was supportive. He is still a donor today. (TMD)

Shortly after this unsolicited media attention, the TMD and TPD collaboratively produced and launched a page on Corel's website, announcing their robotic telemedicine program. They further translated this information into digital presentations and documents to aid the TPD in his efforts to convince rural hospitals to join their telemedicine network. InTouch contributed resources to help ensure this process was persuasive:

I would call to community hospitals to promote this program, "hey Corel has new technology we'd like to show you," [and] InTouch was right there with us [so] we'd be able to do it. We had a [mock hospital] room set up in California, so... we could control a robot there. To see it from the other side, we had a robot in the room and we'd arrange for a rep to dial in to that robot so they could then see the robot, the maneuverability, the camera, how exact it was. It was boots on the ground, getting out there doing a sales pitch to all these different hospitals. We probably got five or six hospitals to take one of the robots." (TPD)

While none of these robotic telemedicine referral relationships survived more than a few years, they sustainably enhanced previous business connections: "where [Corel] had a meaningful relationship, the robot served to strengthen it and served as a nice segue to a more interactive relationship." (TPD). "Interactive," in this context means enhanced inter-institutional connections between physicians, staff and administrators at each 
institution, and in some cases new partnerships that were economically valuable to both parties and beneficial to patients.

These extra-organizational signaling practices were enabled and extended by intra-organizational practices. For example, organizational staff made explicit, public note of the system in front of patients, families, students and other outsiders. They did this opportunistically, in the midst of using the systems to deliver instrumental value:

We recently had an engineer here [as a patient in the ICU], old guy, 91year-old, he was recovering, he was sitting in the chair and he was very bright, so I just surprised him. I drove the robot in and he was so happy and he was so amazed and I knew that he would love it. I wanted to engage him positively and motivate him, you know he had had brain surgery. (ICU Physician)

Nurse [to immobile ICU patient]: you're going to talk to a robot! Second nurse [to patient]: Pretty cool, huh?

Physician [controlling the RP-7]: You look very good, actually! Patient [looking at AP on RP-7 screen]: So do you! Where are you? (Fieldnotes, 01 Dec, 2011)

When I asked about this kind of interaction, staff uniformly indicated they saw and referred to the system as a strong indicator of Corel's technological sophistication and commitment to quality:

I had a patient that was alert and oriented and doing fantastic and she was like, "What is that,' and I explained it to her and she was like super impressed, and I think that just kind of leaves Corel like a check in the, good column like "wow they have the technology here that I would think that they would have in [major city]." So, I thought that was really kind of cool that we have this really advanced technology. (Nurse)

Such "highlighting" practices thus enhanced the employee and customer experience by signaling to all involved that Corel was more committed to cutting edge technology intended to improve patient care. In some cases, these interactions also distinguished Corel from its competitors.

In contrast to these highlighting interactions, staff also worked to limit experiences that contributed to negative interpretations about Corel's investment in the RP-7 systems. The lack of internal and external uptake after the pivot to an ICU use case left most of the RP-7 units literally gathering dust in various hallways in various institutions. Given financial pressures in most of these institutions at this time, the visible presence of this expensive and underutilized equipment in high-traffic locations soon became problematic:

They [hospital administrators] felt like, out of sight, out of mind, and I was told "get "em out of the hospital." Because they sat, plugged in [in public spaces], and weren't being used for the longest time. People knew we were spending a lot of money on those things. People were asking for FTEs [full-time employees] and were getting shot down for this and that and they were saying "You have money for this damn thing and you can't give me a raise? The hell with you!" So, they were like "Get 'em the hell out of there! So now I've got them in a closet. It's terrible. (TPD)
Thus, five additional units were transferred to storage closets, as depicted in Figure 1.

\section{Figure 1: Three RP-7 Units in a Long-Term Storage Room at Corel Hospital in 2011}

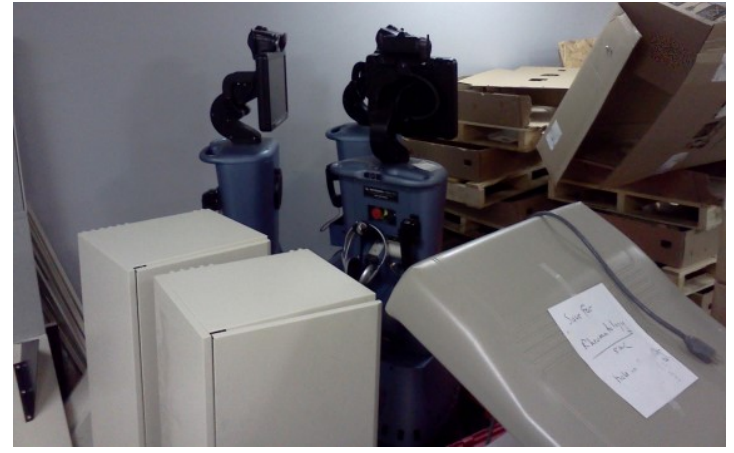

One of these units was removed from storage in 2011 order to allow for separate formal study of the efficacy of robotic telepresence for late-night patient rounding, as contrasted with traditional telephone rounds [45], [46], but this single researchdriven use was completed in 2012 and the units were not used after that time, and all were stored in buildings far away from spaces for potential deployment.

Such "hiding" practices thus reduced workplace conflict over resources by precluding signals that Corel valued inert novel technology over investments in human resources intended to improve patient care. Such interactions also impeded further exploratory attempts to find valuable instrumental uses for the system, as it increased the social and monetary cost of physically deploying of these systems.

Robotic telepresence's value as an organizational signal was further evidenced in InTouch's commitment to its continued robotic telepresence product development, despite numerous deployment outcomes like the one reported here. Sales of their mobile robotic systems did not grow explosively, and InTouch shifted its strategy to focus on secure, cloud-based telemedicine solutions delivered through nonrobotic, repositionable videoconferencing equipment and common handheld devices. These were far more usable in that they rely on well-understood interfaces and infrastructure. Yet InTouch recognized that these were far less obviously symbolic of technical sophistication:

InTouch... have responded and come up with a whole range of products from handheld devices, but they still have a robot on their website, they still have an actual robot that they use. (TPD)

Just as with Corel, InTouch recognized that hospitals - their customer base - needed to signal commitment to the very best care, and in the US market at least this was strongly associated with visible investments in novel technologies. InTouch thus continued to develop and sell far less usable, far more complex robotic technology.

In sum, Corel secured significant signaling value through its "first mover" investment in the RP-7. This sent convincing 
signals to outsiders in a crowded market that it was a cuttingedge institution committed to innovative, top-quality care. These signals proceeded through media divorced from direct observation of regular use and related outcomes such as news stories, web pages, presentations, digital documents and controlled demonstrations. They also proceeded through on-site highlighting and hiding practices, and the latter made it more difficult to find additional instrumentally valuable applications of the technology within the organization. These signals facilitated the acquisition and deepening of revenue-generating business relationships, built brand awareness in a competitive market, drove customer demand, contributed to employee and customer satisfaction and reduced conflict over resources. These findings are depicted in figure 2 .

\section{Limitations and Implications}

The generalizability of these findings is limited by the characteristics of the empirical context under study. Corel was a non-incumbent organization in an intensely competitive market, purchasing technology from a firm that was itself a nonincumbent in a competitive market of its own. It was also difficult for outsiders to surveil the use - and therefore to assess the practical utility - of the robotic systems in question. Signaling dynamics and value should play out similarly in similar conditions - readily seen in a range of security, commercial aviation, manufacturing and construction applications. But it remains to be seen how these findings may apply in contexts with differing characteristics.

It seems likely, for example, that these signaling dynamics will matter more as interpretation and key outcomes become strongly linked (e.g. announcing the purchase of a system may attract or repulse top talent as they seek leading quality indicators to make employment decisions). Further, prior work on novelty effects [47], [48] suggests that signaling value will be higher when robots (and other technologies) are new and rare. This implies that organizations will regularly shift their signaling emphasis to new, rare technologies (e.g. robots) and that this "signaling churn" will vary based on changes in technological novelty. Finally, it seems likely that actors will still extract signaling value from novel robots when they facilitate unambiguous, high and sustained instrumental value [49], [50], but that this will play out in different ways than in my case. Further study is needed to build upon these findings towards theory that accounts for these and likely other sources of variation in technological signaling.

\subsection{Implications for HRI Research}

These limitations aside, this study of robots as signals enriches HRI research in several ways. First and most broadly, theorizing robots as signals can help us make better predictions regarding HRI in complex social settings. Humans and organizations persist by securing resources they value. HRI researchers should presume that actors will sometimes signal worthiness for such resources by interacting in observable ways with a robotic system, perhaps with little regard to the efficacy or instrumental utility of such interactions. And as in this study, such signaling actions may have significant second order HRI effects: successful signaling may confer differential access to valuable resources (e.g. subsequent robot interaction), reduce collective conflict and make it harder to explore new interaction patterns. Thus whether they are focused on group or organizational behavior, HRI researchers can improve study designs by assessing their study contexts for the characteristics that made signaling more salient and consequential in this study: spatial and temporal separation between more direct HRI and practical results, limited observability of such HRI, resource asymmetries (e.g. status, power, financial) between interactants, and interpretive schemes

Figure 2: Instrumental and SIgnaling Value of Robotlc Telepresence at Corel Hospltal, 2007-2012

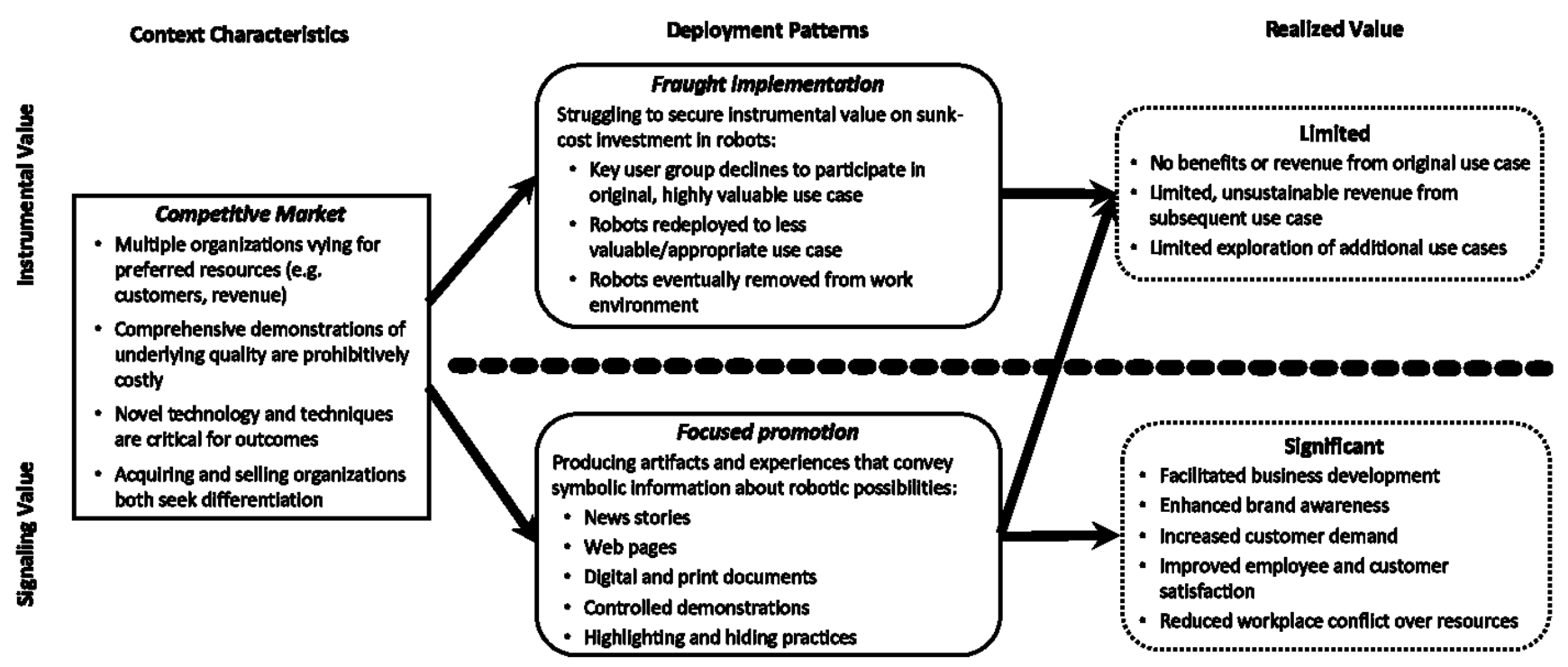


that treat certain interactions with robotic systems as indicators of resource worthiness.

Second, this study also offers useful guidance for researchers focused on improving techniques for developing and fielding robotic systems outside of the lab. While users and bystanders may value a robotic system for the instrumental results it offers (e.g. a clean floor), this work suggests it may be the case that they also - or perhaps primarily - choose to acquire and interact with such a system for related signaling value (e.g. being seen as having disposable wealth). As in this study, public behaviors that flow from a signaling orientation will likely differ from those rooted in a desire to get instrumental results. Applied HRI researchers can take several steps to take these dynamics into account. The first is careful examination of context to determine the consequences of information about interaction with a robotic system versus those associated with direct interaction with that robot. If they discover that signaling effects are likely to be strong and to interfere with standing research aims, HRI researchers have two nonexclusive choices: they can reorient to this as a finding, producing work that enriches our understanding of signaling dynamics in HRI, and they can reconfigure their system, setting and methods to reduce the salience of signaling dynamics as a confound.

Third, and relatedly, this study suggests HRI researchers can produce findings with more external validity by accounting for or even studying - social processes that shape signaling regarding robotic systems. The content and consequences of HRI at Corel were heavily shaped by the signaling dynamics in this study, and these in turn were shaped by formal processes such as marketing, public relations, sales and fundraising, as well as informal practices such as hiding and highlighting. At the least, HRI researchers can enhance the validity of their contributions by accounting for the range of such mechanisms that may shape interpretation and action relevant to the specific context under study. Guiding questions here include: how might systems like these be marketed, sold, bought and depicted before, during and after use? To whom will related information appeal, and which of these actors possesses resources that focal actors desire? How might HRI unfold differently, given answers to these questions? As I did here, HRI researchers may also turn their attention more directly towards these social processes, asking how they interrelate with more direct HRI. Guiding questions here include: how do differences in signaling-related social processes translate into meaningful differences in the HRI phenomena(e) of interest? How does variation in that HRI influence those processes in return? What implications do answers to these questions have for all HRI researchers?

\subsection{Implications for Economics and Organization Studies Research}

Many HRI studies can - but do not - identify contributions to literatures within other social sciences. This study does so for the economics and organization studies literatures. First and most broadly, this paper extends established literature on signaling theory by explicitly considering usable technology rather than information or inert assets - as signals. Prototypical research targets in signaling research - an individual displaying an educational credential on a resume, or a firm's announcement about nonexistent software - do not exhibit the same characteristics, and so the implications above should prompt signaling researchers to revisit this body of theory.

For example, this study suggests careful examination of the couplings between signaling and instrumental value of acquired technology. Corel signaled quality to a crowded market by promoting its acquisition of robotic telepresence technology through presentations, media relations and controlled demonstrations, but it was costly for outsiders to assess actual deployment (or lack thereof), as this would have required ongoing, direct observation of everyday use. And even at this level, highlighting and hiding practices strongly shaped the range of interpretations available to all but the most assiduous observer. It was this gap that allowed Corel to secure signaling value for its investment in robotic telepresence systems, even when instrumental value proved to be poor. And yet - after a failed initial implementation - signaling success greatly impeded subsequent efforts to seek instrumental value through the acquired technology.

This study also suggests that the materiality [51], [52] of a technology is important for the signaling value of that technology. In this case, it was easy to "demo" an RP-7 facilitating familiar tasks, physically executed in space and time resolutions that humans were accustomed to in their own work. This will be true for many robotic systems, given that they are often designed to function within work-related processes that are enacted by humans via physical movement. Relatedly, prior work in HRI [26], [53], psychology [54], [55] and evolutionary biology [56], [57] suggests that humans instinctively classify robots as potential fauna, greatly increasing our attraction, aversion and recall regarding them. This relatively high signaling potency could help explain why modern discourse revolves so heavily around robots when the vast majority of instrumental value and socioeconomic disruption associated with novel technology flows from other advanced technologies such as machine learning, cloud computing and sensor networks, which are distributed, difficult to observe at a glance and often execute their tasks with extraordinary rapidity, relative to human-normal speeds for comparable tasks.

\section{CONCLUSION}

Roman legions polished their shields and swords so enemies could see their glint from miles away [58]. At least since then, organizations have sent signals about the acquisition of ostensibly superior technology to produce valuable outcomes. This study shows that modern organizations can do the same with robotic systems, and that this can occur even when those systems deliver little instrumental value. Such dynamics deserve careful study in an age where information about human-robot interaction figures in increasingly consequential decisions in 
areas such as employment and immigration policy, tax law, education and organization and technological design.

\section{ACKNOWLEDGMENTS}

Many thanks to Sabine Hauert who invited me in 2014 to give a talk at Robots: From Imagination to Market; I derived the core insight in this paper in response. I am also grateful for feedback from Daniel Rock, the Junior Ethnographers of Technology and the candor and forbearance of my informants at Corel hospital.

\section{REFERENCES}

[1] B. Mutlu and J. Forlizzi, "Robots in organizations: the role of workflow, social, and environmental factors in human-robot interaction," in Proceedings of the 3rd ACM/IEEE international conference on Human robot interaction, 2008, pp. 287-294.

[2] M. K. Lee and L. Takayama, "Now, I have a body: Uses and social norms for mobile remote presence in the workplace," in Proceedings of the 2011 annual conference on Human factors in computing systems, 2011, pp. 33-42.

[3] K. Stubbs, P. Hinds, and D. Wettergreen, "Challenges to Grounding in Human-robot Interaction," in Proceedings of the 1st ACM SIGCHI/SIGART Conference on Human-robot Interaction, New York, NY, USA, 2006, pp. 357-358

[4] A. Sauppé and B. Mutlu, "The social impact of a robot co-worker in industrial settings," in Proceedings of the 33rd annual ACM conference on human factors in computing systems, 2015, pp. 36133622.

[5] H. A. Yanco, A. Norton, W. Ober, D. Shane, A. Skinner, and J. Vice, "Analysis of human-robot interaction at the darpa robotics challenge trials," F. Field Robot., vol. 32, no. 3, pp. 420-444, 2015.

[6] M. Jung and P. Hinds, "Robots in the Wild: A Time for More Robust Theories of Human-Robot Interaction," ACM Trans HumRobot Interact, vol. 7, no. 1, pp. 2:1-2:5, May 2018.

[7] L. Summers, "Opinion | Picking on robots won't deal with job destruction," Washington Post, 05-Mar-2017.

[8] K. J. Delaney, "The robot that takes your job should pay taxes, says Bill Gates," Quartz, 17-Feb-2017. [Online]. Available: https://qz.com/911968/bill-gates-the-robot-that-takes-your-jobshould-pay-taxes/. [Accessed: 28-Sep-2019].

[9] S. Nikolaidis, R. Ramakrishnan, K. Gu, and J. Shah, "Efficient model learning from joint-action demonstrations for human-robot collaborative tasks," in Proceedings of the Tenth Annual ACM/IEEE International Conference on Human-Robot Interaction, 2015, pp. 189-196.

[10] C.-M. Huang and B. Mutlu, "Anticipatory Robot Control for Efficient Human-Robot Collaboration," in The Eleventh ACM/IEEE International Conference on Human Robot Interaction, Piscataway, NJ, USA, 2016, pp. 83-90.

[11] M. F. Jung, N. Martelaro, and P. J. Hinds, "Using robots to moderate team conflict: the case of repairing violations," in Proceedings of the Tenth Annual ACM/IEEE International Conference on Human-Robot Interaction, 2015, pp. 229-236.

[12] V. Srinivasan and L. Takayama, "Help me please: Robot politeness strategies for soliciting help from humans," in Proceedings of the 2016 CHI conference on human factors in computing systems, 2016, pp. $4945-4955$.

[13] S. Reig, J. Forlizzi, and A. Steinfeld, "Leveraging robot embodiment to facilitate trust and smoothness," in 2019 14th ACM/IEEE International Conference on Human-Robot Interaction (HRI), 2019, pp. $742-744$.
[14] M. Johnson, M. Beane, D. Mindell, and J. Ryan, "Knowledge Management for Rapidly Extensible Collaborative Robots," in Human Interface and the Management of Information. Visual Information and Knowledge Management, 2019, pp. 503-523.

[15] R. Wilcox and J. Shah, "Optimization of multi-agent workflow for human-robot collaboration in assembly manufacturing," in Infotech@Aerospace 2012, 2012, p. 2535.

[16] J. Casper and R. R. Murphy, "Human-robot interactions during the robot-assisted urban search and rescue response at the world trade center," IEEE Trans. Syst. Man Cybern. Part B Cybern., vol. 33, no. 3, pp. 367-385, 2003.

[17] M. Spence, “Job market signaling," Q. J. Econ., vol. 87, no. 3, pp. 355-374, 1973.

[18] S. R. Barley and G. Kunda, "Bringing work back in," Organ. Sci., vol. 12, no. 1, pp. 76-95, 2001.

[19] B. A. Bechky, "Making Organizational Theory Work: Institutions, Occupations, and Negotiated Orders," Organ. Sci., vol. 22, no. 5, pp. 1157-1167, Sep. 2011.

[20] H. Admoni, T. Weng, B. Hayes, and B. Scassellati, "Robot Nonverbal Behavior Improves Task Performance In Difficult Collaborations," in The Eleventh ACM/IEEE International Conference on Human Robot Interaction, Piscataway, NJ, USA, 2016, pp. 51-58.

[21] A. Rule and J. Forlizzi, "Designing Interfaces for Multi-user, Multirobot Systems," in Proceedings of the Seventh Annual ACM/IEEE International Conference on Human-Robot Interaction, New York, NY, USA, 2012, pp. 97-104.

[22] B. Hayes and J. A. Shah, "Improving Robot Controller Transparency Through Autonomous Policy Explanation," in Proceedings of the 2017 ACM/IEEE International Conference on Human-Robot Interaction, New York, NY, USA, 2017, pp. 303-312.

[23] A. Wagoner et al., "Humanoid robots rescuing humans and extinguishing fires for Cooperative Fire Security System using HARMS," in 2015 6th International Conference on Automation, Robotics and Applications (ICARA), 2015, pp. 411-415.

[24] A. Guneysu Ozgur et al., "Iterative design of an upper limb rehabilitation game with tangible robots," in Proceedings of the 2018 ACM/IEEE International Conference on Human-Robot Interaction, 2018, pp. 241-250.

[25] R. Stricker et al., "Interactive mobile robots guiding visitors in a university building," in 2012 IEEE RO-MAN: The 21st IEEE International Symposium on Robot and Human Interactive Communication, 2012, pp. 695-700.

[26] J. Y. Sung, L. Guo, R. Grinter, and H. Christensen, “"My Roomba Is Rambo': Intimate Home Appliances," UbiComp 2007 Ubiquitous Comput., pp. 145-162, 2007.

[27] V. Venkatesh, M. G. Morris, G. B. Davis, and F. D. Davis, "User acceptance of information technology: Toward a unified view," MIS Q., pp. 425-478, 2003.

[28] P. Anderson and M. L. Tushman, "Technological Discontinuities and Dominant Designs: A Cyclical Model of Technological Change," Adm. Sci. Q., vol. 35, no. 4, pp. 604-633, Dec. 1990.

[29] P. A. David, "The dynamo and the computer: an historical perspective on the modern productivity paradox," Am. Econ. Rev., vol. 80, no. 2, pp. 355-361, 1990.

[30] B. L. Connelly, S. T. Certo, R. D. Ireland, and C. R. Reutzel, "Signaling theory: A review and assessment," f. Manag., vol. 37, no. 1, pp. 39-67, 2011.

[31] T. Erdem and J. Swait, "Brand equity as a signaling phenomenon," f. Consum. Psychol., vol. 7, no. 2, pp. 131-157, 1998. 
[32] J.-L. Dessalles, "Optimal investment in social signals," Evolution, vol. 68, no. 6, pp. 1640-1650, 2014.

[33] M. A. Haan, "Vaporware as a means of entry deterrence," f. Ind. Econ., vol. 51, no. 3, pp. 345-358, 2003.

[34] B. L. Bayus, S. Jain, and A. G. Rao, "Truth or consequences: An analysis of vaporware and new product announcements," 7. Mark. Res., vol. 38, no. 1, pp. 3-13, 2001.

[35] D. Dranove and N. Gandal, "The dvd-vs.-divx standard war: Empirical evidence of network effects and preannouncement effects," f. Econ. Manag. Strategy, vol. 12, no. 3, pp. 363-386, 2003.

[36] M. S. Feldman and J. G. March, "Information in organizations as signal and symbol," Adm. Sci. Q., pp. 171-186, 1981.

[37] J. Vertesi, "Seeing like a Rover: Visualization, embodiment, and interaction on the Mars Exploration Rover Mission," Soc. Stud. Sci., vol. 42, no. 3, pp. 393-414, Jun. 2012.

[38] M. Beane, "Shadow Learning: Building Robotic Surgical Skill When Approved Means Fail," Adm. Sci. Q., vol. 64, no. 1, pp. 87123, Mar. 2019.

[39] M. Barrett, E. Oborn, W. J. Orlikowski, and J. Yates, "Reconfiguring boundary relations: Robotic innovations in pharmacy work," Organ. Sci., vol. 23, no. 5, pp. 1448-1466, 2012.

[40] S. R. Barley, "Technology, power, and the social organization of work: Towards a pragmatic theory of skilling and deskilling," Res. Sociol. Organ., vol. 6, pp. 33-80, 1988.

[41] “Drug Can Stop Strokes, But Most Patients Don't Get It," NPR.org. [Online].

Available: https://www.npr.org/templates/story/story.php?storyId=12103226 9. [Accessed: 26-Jul-2019].

[42] A. D. Abbott, Methods of discovery: heuristics for the social sciences. New York: W.W. Norton \& Co., 2004.

[43] H. S. Becker, "The epistemology of qualitative research," Ethnogr. Hum. Dev. Context Mean. Soc. Inq., vol. 27, pp. 53-71, 1996.

[44] R. K. Merton, "Social structure and anomie," Am. Sociol. Rev., vol. 3, no. 5, pp. 672-682, 1938.

[45] M. I. Beane and W. J. Orlikowski, "What Difference Does a Robot Make? The Material Enactment of Distributed Coordination," Organ. Sci., vol. 26, no. 6, pp. 1553-1573, Oct. 2015.
[46] M. Bettinelli, Y. Lei, M. Beane, C. Mackey, and T. N. Liesching "Does Robotic Telerounding Enhance Nurse-Physician Collaboration Satisfaction About Care Decisions?," Telemed. EHealth, vol. 21, no. 8, pp. 637-643, 2015.

[47] C. V. Smedegaard, "Reframing the Role of Novelty within Social HRI: from Noise to Information," in 2019 14th ACM/IEEE International Conference on Human-Robot Interaction (HRI), 2019, pp. 411-420.

[48] E. M. Rogers, Diffusion of Innovations, 5th Edition, 5th edition. New York: Free Press, 2003.

[49] R. R. Murphy, "Human-robot interaction in rescue robotics," IEEE Trans. Syst. Man Cybern. Part C Appl. Rev., vol. 34, no. 2, pp. 138153, 2004.

[50] A. Kuss, R. Hollmann, T. Dietz, and M. Hägele, "Manufacturing knowledge for industrial robot systems: Review and synthesis of model architecture," in 2016 IEEE International Conference on Automation Science and Engineering (CASE), 2016, pp. 348-354.

[51] W. J. Orlikowski and S. V. Scott, "Sociomateriality: challenging the separation of technology, work and organization," Acad. Manag. Ann., vol. 2, no. 1, pp. 433-474, 2008.

[52] P. M. Leonardi, "Theoretical foundations for the study of sociomateriality," Inf. Organ., vol. 23, no. 2, pp. 59-76, Apr. 2013.

[53] K. Darling, “Who's Johnny?' Anthropomorphic Framing in Human-Robot Interaction, Integration, and Policy," Social Science Research Network, Rochester, NY, SSRN Scholarly Paper ID 2588669, Mar. 2015.

[54] C. E. Amiot and B. Bastian, "Toward a psychology of humananimal relations.," Psychol. Bull., vol. 141, no. 1, p. 6, 2015.

[55] V. Sevillano and S. T. Fiske, "Animals as social objects," Eur. Psychol., 2016.

[56] D. S. Goldstein and I. J. Kopin, "Evolution of concepts of stress," Stress, vol. 10, no. 2, pp. 109-120, 2007.

[57] W. B. Cannon, The Wisdom Of The Body, Rev. and Enl. Ed edition. New York: W. W. Norton \& Company, 1963.

[58] T. Livy and A. H. McDonald, Rome and the Mediterrean: The History of Rome from Its Foundation, Books 31-45, 1st edition. Harmondsworth: Penguin Classics, 1976. 